\title{
BIO-Vivencias: un circuito interactivo para promover la alfabetización científica
}

\author{
María Silvina Reyes ${ }^{(1,2)}$ \\ Dora Inés Granados Orellano ${ }^{(1,2)}$ \\ Wanda Polla $(3,4)$ \\ Mariana Perticará (5)
}

(1) Cátedra de Química

General e Inorgánica. Facultad de Humanidades y Ciencias.

(2) Escuela de Nivel Inicial y Primario de la Universidad Nacional del Litoral.

(3) Cátedra de Morfofisiología Vegetal. Facultad de Humanidades y Ciencias.

(4) Dirección de Extensión. Facultad de Humanidades y Ciencias.

(5) Dirección de Comunicación. Facultad de Humanidades y Ciencias. sreyes@gigared.com
La Facultad de Humanidades y Ciencias es una institución reconocida por su larga trayectoria en la formación docente, tiene sus orígenes en la década del 50, siendo una entidad responsable en la conducción pedagógica en la región. En su propuesta académica intervienen áreas de las Ciencias Naturales y Exactas, Ciencias Sociales, Humanidades y Artes. Por propia iniciativa las instituciones educativas deben convertirse en referentes de cambio que la sociedad reclama, consensuando con sus propias comunidades. En este crecimiento y desarrollo institucional, las cátedras tuvieron que reajustarse a cambios producidos en el tiempo y a las nuevas demandas sociales, replanteándose nuevas estrategias de construcciones pedagógicas.

En las propuestas desarrolladas para llevar adelanta estas experiencias, el énfasis estuvo puesto tanto en atender las nuevas exigencias sociales para la formación docente, como en la incorporación de ideas y productos de la tecnociencia, los cambios científicos ocurridos en las disciplinas y el conocimiento como instrumento de abordaje de la realidad para su comprensión. Los nuevos problemas científicos como el desarrollo de los modos de vida, son cambios permanentes, rápidos y profundos, que obligan a prever nuevas adaptaciones curriculares. 
La tarea de enseñar y aprender Ciencias Naturales se encuentra hoy con el desafío de las nuevas alfabetizaciones. En este contexto, entendemos por alfabetización científica una propuesta de trabajo que implica generar situaciones de enseñanza que recuperen las experiencias de los chicos con los fenómenos naturales, para que vuelvan a preguntarse sobre ellos y elaboren explicaciones utilizando los modelos de las ciencias naturales. La universidad debe ser un espacio de diálogo e intercambio entre diversas formas de ver, de hablar y de pensar el mundo, donde se pone en juego los distintos conocimientos que han construido sobre la realidad. Por eso, enseñar ciencias significa abrir una nueva perspectiva para mirar; una perspectiva que permite identificar regularidades, hacer generalizaciones e interpretar cómo funciona la naturaleza. Significa también promover cambios en los modelos de pensamiento iniciales de los alumnos para acercarlos progresivamente a representar esos objetos y fenómenos mediante modelos teóricos. Enseñar ciencias es, entonces, tender puentes que conecten los hechos familiares o conocidos por los chicos con las entidades conceptuales construidas por la ciencia para explicarlos. Por lo expuesto anteriormente, desde la cátedra de Química General e Inorgánica y las direcciones de Extensión y Comunicación de la Facultad de Humanidades y Ciencias de la Universidad Nacional del Litoral nos propusimos llevar a cabo un circuito interactivo al cual denominamos BIO-Vivencias, la iniciativa pretendió favorecer el intercambio entre la universidad y las escuela, motivar la curiosidad por diferentes fenómenos biológicos e incentivar vocaciones científicas. El recorrido se llevó a cabo los días 4 y 5 de octubre de 2012 en el horario de 9 a 17 hs. El sendero contó con 9 estaciones donde se propuso a los visitantes diferentes actividades, juegos, charlas, proyecciones, observaciones utilizando el microscopio y/o lupa, autoexperiencias de química, física y genética, entre otros. Los nombres de las distintas estaciones fueron los siguientes:

(1) Isla naturaleza: la aventura de aprender jugando.

(2) Conservación de la biodiversidad: Jaakanigás, humedal sobre el río Paraná.

(3) Imperceptible belleza de lo cotidiano.

(4) La reserva va a la escuela.

(5) Abejas: Insectos laboriosos.

(6) Microorganismos que habitan en una gota de agua dulce. 
(7) Inflador químico.

(8) Y el ADN, ¿qué tiene que ver?

(9) Preparación de materiales fotorresistentes, imitando lo que ocurre en el ADN.

Desde la dirección de comunicación se diseñó un logo el cual acompañó cartelería, folletería e indumentaria de los guías. La realización de BIO-Vivencias contó con la colaboración de alumnos, pasantes, docentes e investigadores de las carreras de Licenciatura en Biodiversidad y Profesorado en Biología. La experiencia tuvo una excelente convocarla y activa participación de más de 500 alumnos entre 11 y 15 años de edad, de toda la provincia de Santa Fe. 